\title{
Pleksiform Miksoid Gastrointestinal Stromal Tümör, İnce Barsak Yerleşimli Nadir Bir Histolojik Patern: Olgu Sunumu
}

\section{${ }^{1}$ Leymune Parlak, ${ }^{1}$ Rabia Altunbaş, ${ }^{1}$ Erdem Özdemir, ${ }^{1}$ Emine Zeynep Tarini, ${ }^{2}$ Buket Gedik}

SBÜ. Mehmet Akif İnan Eğitim ve Araştırma Hastanesi, Patoloji Bölümü, Şanlıurfa, Türkiye

2 Şanlıurfa Eğitim ve Araştırma Hastanesi, Patoloji Bölümü, Şanlıurfa, Türkiye

\section{Correspondence:}

Leymune PARLAK

SBÜ. Mehmet Akif İnan Eğitim ve

Araştırma Hastanesi, Patoloji

Bölümü, Şanlıurfa, Türkiye

e-mail: leymune_38@hotmail.com

\section{Özet}

Gastrointestinal stromal tümör (GİST) gastrointestinal sistemin en sik görülen, kajal hücrelerinden köken alan mezenkimal tümörüdür. Sıklıkla 50 yaş sonrası ve \%60 oranında midede, ikinci sıklıkla jejunum ve ileumda (\%30) görülür. İnce barsak yerleşimliler midede bulunanlara göre \% $40-50$ daha fazla malign seyirlidir. Ayrıca ince bağırsak GISTleri mide GISTleri gibi ayırt edici histolojik alt tipler oluşturmazlar. Çoğunlukla iğsi hücrelidirler. Epiteloidler ise çok küçük bir kısmını oluşturur. Bizim sunacağımız olguda epiteloid ve iğsi hücre özelliklerine ek olarak pleksiform büyüme paterni ve zeminde miksoid stroma bulunmaktadır.

Anahtar Kelimeler: GISTT, İnce barsak, Pleksiform, Miksoid

\section{Abstract}

Gastrointestinal stromal tumor (GIST) is the most common mesenchymal tumor of the gastrointestinal system originating from cajal cells. It is frequently seen after the age of 50 and $60 \%$ in the stomach, the second most frequently in the jejunum and ileum (30\%). Small bowel residents have 40-50\% more malignant prognosis than those in the stomach. In addition, small intestine GISTs do not constitute distinctive histological subtypes like gastric GISTs. They are mostly spindle cell. Epithelioids, on the other hand, constitute a very small part. In our case, in addition to epithelioid and spindle cell features, there is a plexiform growth pattern and myxoid stroma in the ground.

Keywords: GİST, Small bowel, Plexiform, Myxoid 


\section{Giriş}

İnce barsaklar gastrointestinal mukozanın yaklaşık \%90'ını ve gastrointestinal tractın total uzunluğunun \%75'ini oluşturmasına rağmen tümörleri tüm gastrointestinal kanserlerin \%5'inden azını oluşturur. İnce barsak kanserlerinin lokalizasyona göre görülme oranları duodenum \%55-82, jejunum \%11-25, ileum \%717'dir. Histopatolojik olarak adenokarsinom $\% 40$ '1n1, nöroendokrin tümörler \%40'1n1, gastrointestinal stromal tümör, lenfoma ve sarkomlar ise \%20'sini oluşturur (1).

Gastrointestinal stromal tümör (GISST) gastrointestinal sistemin en s1k görülen, kajal hücrelerinden köken alan mezenkimal tümörüdür. S1klıkla 50 yaş sonrası ve $\% 60$ oranında midede, ikinci sıklıkla jejunum ve ileumda (\%30) görülür. En s1k mutasyonlar c-KİT ve Platelet Derived Growth Factor Receptor Alpha (PDGFRA) geninde izlenir. İnce barsak yerleşimliler midede bulunanlara göre \%40-50 daha fazla malign seyirlidirler. Histolojik yapıları çoğunlukla iğsi olsa da epiteloid ve mikst iğsi-epiteloid tipte de olabilir. İnce barsak GIST'lerinde immunohistokimyasal (IHH) CD117 ve CD34 pozitifliği görülür (2). Bizim sunacağımız olguda epiteloid ve iğsi hücre özelliklerine ek olarak pleksiform büyüme paterni ve zeminde miksoid stroma bulunmaktadir. $\mathrm{Bu}$ nadir histolojik özellikleri ve ayırıcı tanılarını sunmayı amaçladık.

\section{Olgu}

Elli iki yaşında erkek hasta karın ağrısı şikayeti ile hastanemize başvurdu. Yapılan tüm batın bilgisayarlı tomografisi 'Pelvik bölgede her iki alt kadrana uzanım gösteren yaklaşık 162x126 $\mathrm{mm}$ boyutunda heterojen yoğun kontrastlanan lobule kontürlü hipodens lezyon izlenmiştir.'olarak yorumlandi. Kitle rezeksiyonu yapıldı. Patoloji isteminde ön bilgi olarak 'ileoçekal valvin $120 \mathrm{~cm}$ proksimalinde mesaneye yapışık kitle' yazmaktaydı. Patolojiye gönderilen materyalin makroskopik incelemesinde $4,5 \mathrm{~cm}$ uzunluğunda ince barsak segmentinin serozal bölgesinde $18 \times 16 \mathrm{~cm}$ ölçülerinde, multinodüler, kesit yüzeyi kanamalı, nekrotik ve solid alanlar içeren lezyon görüldü (Resim 1). Örneklenen parçaların 1 şık mikroskobunda hematoksilen-eozin boyalı lamlarının incelenmesinde ince barsak serozal yağlı dokudan kaynaklanan, muskularis propriaya bitişik pleksiform nodüler lezyon izlendi. Tümör miksoid zeminde iğsi veya oval, intrastoplazmik vakuol içeren hücreler ve ince damar yapılarından oluşmaktaydı (Resim 2-3). Nekroz ve lenfovasküler tümör invazyonu izlendi. Mitotik aktivite $1 / 50$ büyük büyütme sahas1 olarak sayıldı. İmmunohistokimyasal boyamalardan Vimentin, CD117, DOG-1 ve CD34 ile yaygın pozitiflik, S100 ile fokal tek tük hücrede pozitiflik görüldü (Resim 4). SMA, Desmin, PanCK ile negatif sonuç elde edildi. Ki67 proliferasyon indeksi \%3-5 civarındaydı. Vaka yerleşim yeri, histopatolojik ve immunohistokimyasal bulguların desteği ile 'Pleksiform miksoid gastrointestinal stromal tümör' olarak yorumland. Armed Forces Institute Studies Prior (AFIP)'e göre risk grubu 3b/ yüksek riskli prognostik grup şeklindeydi

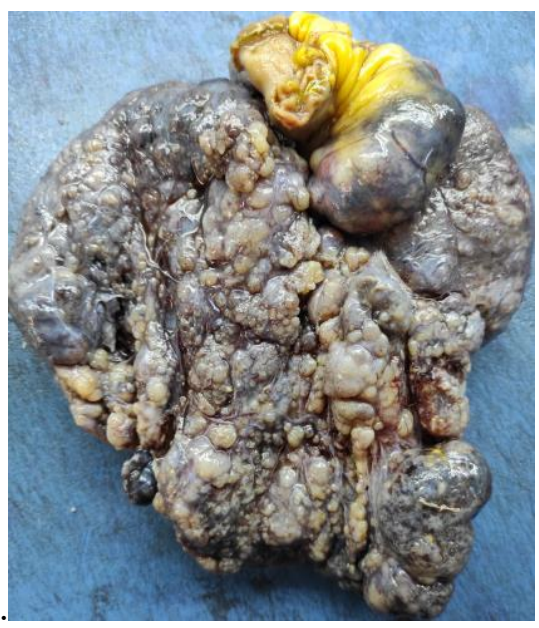

Resim 1. İnce barsak segmentinin serozasından köken alan dış yüzünde nodüler yapılar bulunan kitle. (Makroskopik görünüm) 


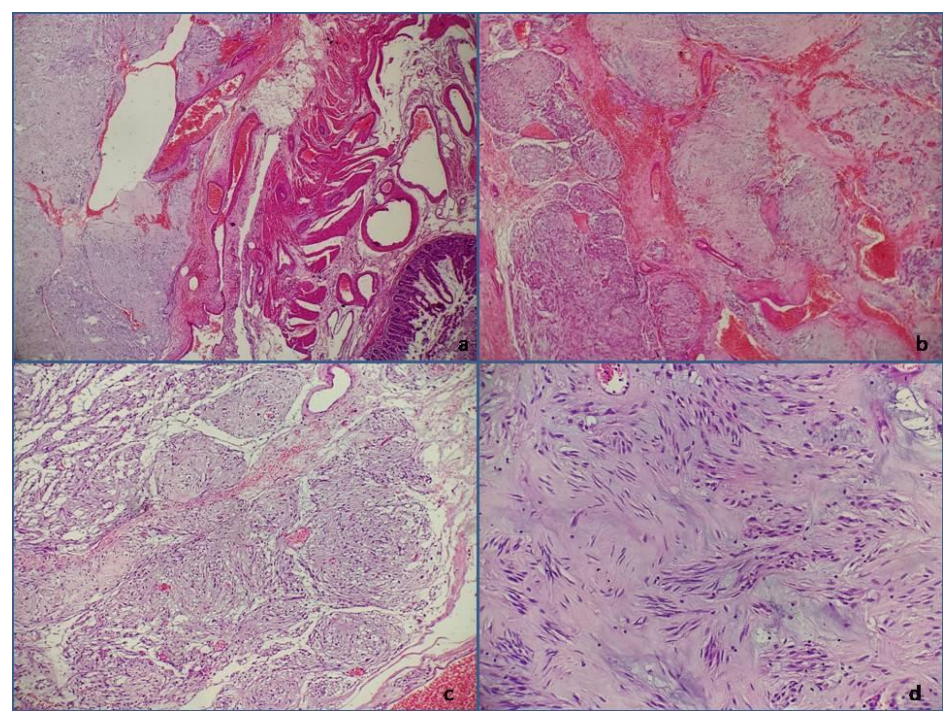

Resim 2. a: İncebarsak muskularis propriaya yapışık seroza yerleşimli lezyon (HE, 40x) b ve c: Pleksiform büyüme paterni (HE, b:40x, c:100x) $\mathrm{d}$ : Pleksiform alanlardaki iğsi hücreler (HE, 400x)

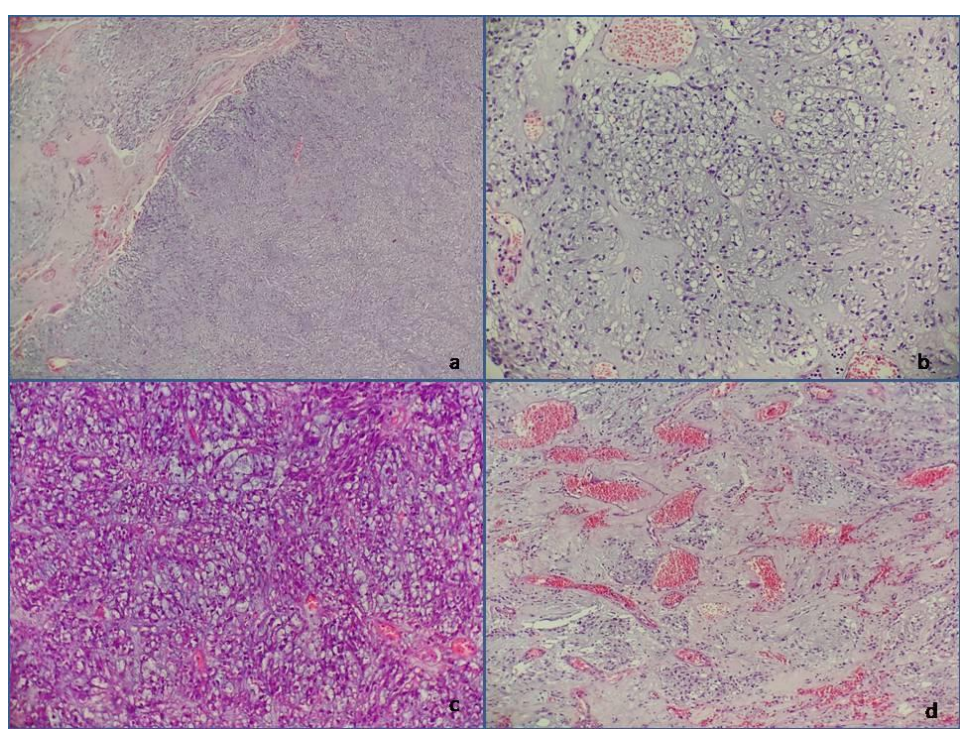

Resim 3. a: Daha solid ve soluk boyanmış tümöral alanlar (HE, 40x) b ve c: Miksoid zeminde oval, intrastoplazmik vakuol içeren hücreler (HE, 100x) d: Çok sayıda ince vasküler yapılar ve arada epiteloid oval tümöral hücreler (HE,40x) 

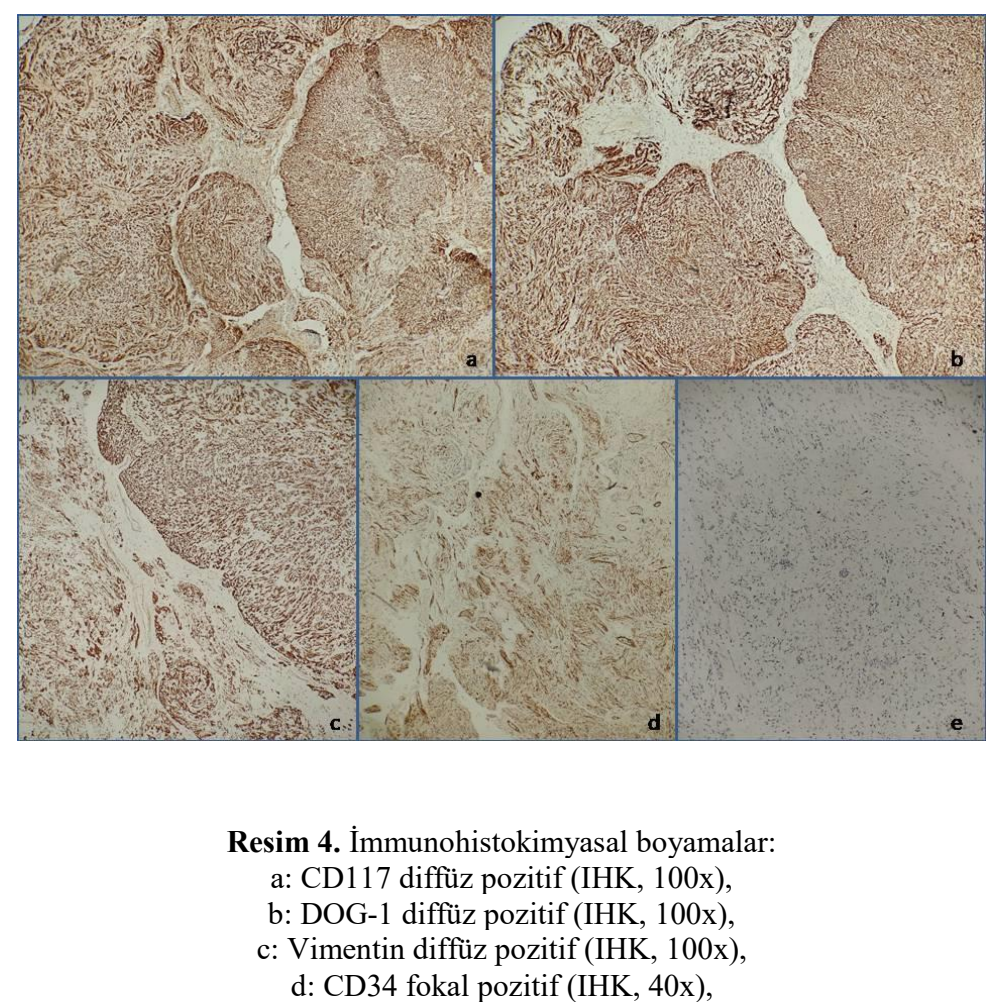

\section{Tartışma}

e: S100 fokal tek tük hücrede pozitif (IHK, 100x)

Gastrointestinal stromal tümörler tamamen asemptomatik olabileceği gibi yerleşim yeri, tümörün büyüklüğü, mukozal ülser ve nekroz varlığına bağlı olarak ağrı, gastrointestinal kanama, ele gelen kitle, kusma, anemi, ileus gibi semptomlar gösterebilirler (3). Bizim hastamız hastaneye karın ağrısı ile başvurmuştu ve yapılan radyolojik görütülemelerde kitle tespit edilerek opere edilmişti.

GIST'lerin potansiyel biyolojik davranışını belirlemek için AFIP kriterleri kullanılmaktadır. $\mathrm{Bu}$ kriterler tümör boyutu $(\leq 2 \mathrm{~cm},>2 \leq 5 \mathrm{~cm},>5$ $\leq 10 \mathrm{~cm}$ ve $>10 \mathrm{~cm})$ ve 50 büyük büyütme sahasinda (BBS) sayılan mitoz sayısina $(\leq 5 / 50$ BBS ve $>5 / 50$ BBS) göre verilmektedir. Gastrik ve ince barsak GIST'leri bu verilere göre çok düşük, düşük, orta, yüksek riskli gruplara ayrılmaktadır (4). Bizim olgumuzun tümör boyutu $18 \mathrm{~cm}$ ve mitoz sayıs $1 / 50$ BBS idi. Bu veriler ile ince barsak GIST AFIP risk grubu 3b/ yüksek riskli prognostik grup olarak değerlendirildi.

Gastrik GIST'lerin 8 farklı ayırt edici histolojik alt tipi vardır. Bunlar sklerozan iğsi hücreli subtip, palizatlanan vakuollü iğsi hücreli subtip, hipersellüler iğsi hücreli subtip, sarkomatöz iğsi hücreli subtip, sklerozan epiteloid varyant, diskoheziv epiteloid subtip, hipersellüler epiteloid subtip ve sarkamotöz epiteloid subtiptir. Oysa ki ince barsak GIST'leri mide GIST'leri gibi ayırt edici histolojik alt tipler oluşturmazlar. Çoğunlukla iğsi hücrelidirler. Epiteloid patern ise sadece \%5'ini oluşturur (5). Bizim olgumuzda iğsi ve epiteloid miks tipte histolojik yapıya ek olarak pleksiform büyüme paterni ve miksoid zemin izlenmiştir.

GİST'lerin normalde yetişkin barsağında myenterik pleksusun içinde ve etrafinda gastrointestinal sistem peristaltizmini düzenleyen interstisiyel cajal hücrelerinin prekürsörlerinden kaynaklanan mezenkimal tümörler olduğu düşünülmektedir (6). Hirato ve ark 1998 yılında GiST'lerin \%80'inden fazlasında tirozin kinaz reseptörü kodlayan c-kit gen mutasyonunu göstermiştir. C-kit proteini Kajal hücrelerinde bulunmaktadır ve immunohistokimyasal olarak CD117 ile \%95 oranında ekspresyonu rapor edilmiştir (7). Ancak malign melanom, adenoid kistik karsinom, Merkel hücreli karsinom, Kaposi sarkomu, liposarkom ve hatta leiomyosarkom (nadiren) gibi diğer tümörlerde de eksprese edilebilir. $\mathrm{Bu}$ nedenle 2004 y1lında DOG-1 immun markerı keşfedilmiştir. DOG-1 ve CD117 kombinasyonu GiST'lerin \%98'inden fazlasinda tanı koydurucudur. Ayrıca CD34 pozitifliği de tanıya yardımcidır (8). Bizim vakamız da immunohistokimyasal olarak CD117, DOG-1 ve CD34 pozitifliği görüldü.

Bazı GIST'lerde c-kit mutasyonu yerine başka bir tirozin kinaz protoonkogeni olan PGFRA 
geninde mutasyon tespit edilebilir (6). Ayrica gastrik epiteloid GíST'lerde suksinat dehidrojenaz (SDH) enzim eksikliği de görülebilir. $\mathrm{Bu}$ enzim defekti pleksiform multinodüler özelliklerdeki GIST'lerde görülse de incebarsak GİST'lerinde görülmez. Bunlar imatinibe direnç gösterir ve mevcut risk değerlendirmeleri ile klinik davranışı belirlenemez (9). Bizim olgumuz 6 aydır takipte ve nüks izlenmedi. Bölümümüzde moleküler çalışma yapılamadığı için mutasyon varlığına bakamadik. Ancak pleksiform morfolojisine rağmen ince barsak yerleşimi ile SDH enzim eksikliği olamayacağını düşünmekteyiz.

Ayırıc1 tanıda miksoid zeminiyle miksoid liposarkomdan, pleksiform büyüme paterni ile de nörofibrom, schwannom, pleksiform fibrohistiositik tümörlerden ayırt etmek gereklidir (10). Miksoid liposarkom intraperitoneal görüldügünnde öncelikle metastaz düşünülmelidir. Ayrica immunohistokimyasal olarak MDM2 ve CDK4 pozitiftir (11). Pleksiform schwannom kutanöz bir tümör olmasına rağmen visseral bölgede de bulunabilir. Miksoid değişiklikler ve nekroz içerebilir. S100 pozitifliği ve CD117 negatifliği ile GIST'den ayrilır. Pleksiform nörofibrom da pleksiform shwannoma ile benzer immunohistokimyasal özellikler taşır (12). Pleksiform fibrohistiositik tümörler yine kutanöz yerleşimli ve CD68 pozitiftir (13).

\section{Sonuc}

Özellikle batın içi yerleşimli mezenkimal tümörlerde miksoid zeminde ve pleksiform yapıda da GIST olabileceği akılda tutulmalıdır. İHK olarak desteklemek için CD117, CD34, DOG-1 immun panele eklenmelidir. Özellikle miksoid zeminiyle miksoid liposarkomdan, pleksiform büyüme paterni ile de nörofibrom, schwannom, pleksiform fibröz histiositomdan ayırt etmek gereklidir. İHK çalışmalarla sonuç alınamaz ise genetik mutasyonlar ve tipik pleksiform mural gelişimi gösteren Suksinat dehidrojenaz (SDH) yetmezliği bakılabilir.

\section{KAYNAKLAR}

1. Barsouk A, Rawla P, Barsouk A, Thandra KC Epidemiology of Cancers of the Small Intestine: Trends, Risk Factors, and Prevention. Med Sci. 2019;7:46.

2. Jumniensuk C, Charoenpitakchai M Gastrointestinal stromal tumor: Clinicopathological characteristics and pathologic prognostic analysis. World J Surg Oncol. 2018;16:1-9.

3. Peng F, Liu Y. Gastrointestinal stromal tumors of the small intestine: Progress in diagnosis and treatment research. Cancer Manag Res. 2020;12:3877-89.

4. Miettinen M, Lasota J. Gastrointestinal stromal tumors: Review on morphology, molecular pathology, prognosis, and differential diagnosis. Arch Pathol Lab Med. 2006;130:1466-78.

5. Miettinen M, Lasota J. Gastrointestinal stromal tumors: Pathology and prognosis at different sites. Semin Diagn Pathol. 2006;23:70-83.

6. Bulu H, Aydin A, Yavuz A, Tanto U, Kuru S, Co A. RevieGastrointestinal Stromal Tümörler: Derleme Gastrointestinal Stromal Tumours : a. 2012;6:101-107.

7. Tornillo L. Gastrointestinal stromal tumor - an evolving concept. Front Med. 2014;1(NOV).

8. Wu CE, Tzen CY, Wang SY, Yeh CN. Clinical diagnosis of gastrointestinal stromal tumor
(Gist): From the molecular genetic point of view. Cancers (Basel). 2019;11:1-15.

9. Giustiniani MC, Papa V, Martini M, et al. Plexiform architecture in gastrointestinal stromal tumors is not restricted to succinate dehydrogenase-deficient cases. Hum Pathol Case Reports. 2018;13:69-72.

10. Li B, Zhang QF, Han YN, Ouyang L. Plexiform myxoid gastrointestinal stromal tumor: A potential diagnostic pitfall in pathological findings. Int J Clin Exp Pathol. 2015;8:13613-618.

11. Setsu N, Miyake M, Wakai S, et al. Primary Retroperitoneal Myxoid Liposarcomas. Am $J$ Surg Pathol. 2016;40:1286-90.

12. Prakash S, Antonescu CR. Deep-Seated Plexiform Schwannoma. 2005;10021:1042-48.

13. Shannalee R. Martinez, Maresha S. Gay and LZ. 乳鼠心肌提取 HHS Public Access. Physiol Behav. 2016;176:139-48. 